\title{
School Nursing in the News
}

\author{
Beatrice J. Kalisch, Philip A. Kalisch, Mary McHugh
}

\begin{abstract}
This study investigated the image of school nursing in the American press during 1978 and 1980. Content analysis of newspaper articles yielded specific measurements of the extent to which school nursing is visible via the press, the content of messages disseminated to the public about school nursing issues and iwo year changes in newspaper treatment of this topic. The mean number of arvicles published per state was 1.43 in 1978 and 6.30 in 1980. The typical school nurse article appeared in a daily newspaper circulated to less than 10,000 readers. Artictes nublished in 1978 were significantly larger than those published in 1980 and wers more likely to focus primarily on the school nursing program rather than on teachers, school boards, funding concerns or other issues. The majority of the articles $(77 \%)$ devoted some space to describing the services provided by school nurses. Nearly $30 \%$ of the articles reported problems with funding for school nursing programs and $21 \%$ reported threatened or actual loss of funding for services.

Alshough reports of protests against budget cuts by school nurses, teachers. administrators and parents were found, parents were depicted as the only interest group 10 succeed in efforts to avert the loss of services. Criticism of school nursing services was found in only $2 \%$ of the articles. More than $80 \%$ of the urtictes mraised school nursing as a vital force for improving the health of American school children. It was concluded that school nursing has not yet altained a position on the public agenda as an important community issue despite the fact that the quality and level of school health services are increasingly threatened in the current budget-cuting climate.*
\end{abstract}

\section{INTRODUCTION}

The image of school nurses in newspapers has much to do with the advancement and effectiveness of our nation's school nursing programs. Economic constraints are forcing school boards across the country to make painful choices about the educational and extacurricular services provided by schools. ${ }^{1}$ The degree that school nursing programs are hindered by financial constraints will be determined to a great extent by public support for these services. In a recent study, Resnick, Blum and Hector noted a widespread misunderstanding of the school nurse's role and a need for enhanced understanding by teachers, parents and administrators. ${ }^{2}$ Taxpayer support for school nursing is contingent upon public perception of its value, and consequently, newspapers, as the primary source of public information about issues pertaining to the local school system, can have a powerful influence on the public's perception of the value of school nursing services.

In order to assess the value of school nursing services, the public must have information about the types of services provided, and the consequences should those

"Thin sudy was supported by a Research Gran NU O088I. "Information Qualiy of Nursing News," from the U.S. Public Health Service. Health Bisources Administation, Bureau of Healih Professions. services be lost. Consumers need to be aware that school children are in the process of developing health habits that will endure throughout adulthood.

School nurses are in a key position to influence child and adolescent health habits by providing health promotion and disease prevention programs. Emphasis on immunization against infectious disease, detection of child abuse and neglect, identification of mental health problems, nutrition education and teaching prenatal care (one-fourth of American teen-age girls have had at least one pregnancy by age 19) are just a few of the essential services offered by school nurses. Accidents are the leading cause of death for children age 5 to $14 .^{3}$ School nurses save lives and prevent disabling injuries by teaching "safety-first" and by monitoring the school environment for hazards. In a real sense, threats to the quality - even the continued existence - of school nursing services may constitute a risk to the future health of the nation.

The purpose of this study was to investigate the quality and amount of information about school nurses and their services contained in newspapers. The following questions for the study were formulated: 1) Where and to what extent are school nursing programs visible to the public via the press?; 2) What specific information is being conveyed to the public about school nursing issues?; 3) To what extent are school nurses and their services presented in a positive and supportive manner versus a negative and nonsupportive manner in newspapers?; 4) What changes occurred in the presentation of school nursing from 1978 to 1980?; and 5) What differences exist in newspaper coverage of school nursing versus other clinical nursing specialties?

\section{METHOD}

The content analysis research methodology was used in this study. ${ }^{4-7}$ Content analysis of news articles provided specific measurement of the messages disseminated to the public about various nursing issues. Newspapers are especially important in providing information about matters that are of local interest, such as public school issues. This study of the quality of news about school nursing communicated via the nation's newspapers is part of a comprehensive study of the information quality of all nursing news. 


\section{Sample}

A nationwide clipping service was employed to clip all newspaper articles about nurses and nursing; each clipping included name, location and circulation of the newspaper, date of publication and page placement within the publication. According to the service's estimates, they locate approximately $80 \%$ of all articles on any subject they clip. To validate this premise, the project subscribed to an additional clipping service for three months. Results of comparisons of the two clipping services showed that $73 \%$ of all articles were identical for each service. No clipping service differences were found for the variables under study.

\section{Procedures}

The News Analysis Tool, which included sections dealing with dissemination, audience exposure, subject of the article and themes important to the quality of nursing news, was developed and tested for use in the project. Coders wre recruited and trained to apply the tool to the newspaper articles. All coders underwent a standardized training program prior to the actual coding of the data. Intrarater reliability was determined by having coders recode a randomly selected sample of articles several months apart, without access to the original coding sheets. Intrarater reliability across all coders and all items was $\mathbf{9 3 \%}$. Interrater reliability was determined by having all coders analyze a sample of randomly selected articles. Interrater reliability across all coders and all items was $94 \%$.

Each school nursing article was reanalyzed for specific content. A list of content areas was generated from the articles by one coder and a count of topics discussed was tabulated for each article. The process was repeated several months later without access to prior results. Agreement between the two codings was $94.2 \%$.

\section{RESULTS}

\section{Dissemination}

The number of articles about all aspects of professional nursing increased $278 \%$ from 1978 to 1980 . Articles about school nursing not only exhibited a similar increase but actually showed a greater percentage increase than any other clinical nursing subspeciality (Table 1).

The growth in the absolute number of articles on school nursing was not uniformly distributed throughout the United States, although all regions showed increases. The greatest increases in absolute numbers of articles were seen in the West North Central Region (17\% of the 1978 articles vs. $25 \%$ in 1980 articles), and the New England Region (7\% in 1978 vs. $16 \%$ in 1980). When the concentration of articles per 1 million of pop- ulation in the regions was considered, the greatest increases were seen in the New England and West South Central regions (Table 2). Despite the numerical increases in newspaper articles about school nursing, it should be noted that the absolute number of articles was still rather small in 1980. An average of only 6.3 articles were published in each state during all of 1980 (only a negligible 1.43 articles were published per state in 1979).

\section{Audience Exposure}

The average circulation of newspapers that contained articles about school nursing was approximately 7,500 readers for the two combined study years. This was significantly smaller than the mean circulation $(12,400$ readers) for all other articles about nursing to appear in newspapers $[\mathrm{t}(16888)=6.60, \mathrm{p}<.0001]$. Even when clinical nursing articles alone are considered $(\mathrm{X}=\mathbf{8 , 8 0 0}$ readers), the school nursing readership is still significantly smaller $[\mathrm{t}(3280)=3.06, \mathrm{p}<.01]$. When the two study years were examined, it was found that circulation of school nursing articles declined from 9,000 readers in 1978 to 7,000 readers in $1980[t(370)=2.13$. $\mathrm{p}<.05]$.

A similar pattern was found in the publication frequency of newspapers in which school nursing articles were found. The mean publication frequency of newspapers that published articles about school nursing was significantly lower than all other nursing topics $[\mathrm{t}(3455)=3.17, \mathrm{p}<.0001]$, and of other clinical nursing topics $[\mathrm{t}(3455)=3.17, \mathrm{p}<.01]$. Publication frequency of newspapers that published school nursing articles did not change from 1978 to 1980. Approximately $50 \%$ of the articles were published in daily newspapers, and another $40 \%$ were found in weekly papers.

General news articles were the most common type of stories for school nursing $(70 \%)$, with feature stories

\begin{tabular}{|c|c|c|c|}
\hline \multicolumn{4}{|c|}{$\begin{array}{c}\text { Table } 1 \\
\text { Newspaper Articles about Clinical Nursing Topics: } \\
1978 \text { and } 1980\end{array}$} \\
\hline \multicolumn{4}{|c|}{$\begin{array}{c}\text { Number and Percent } \\
\text { of Articles }\end{array}$} \\
\hline Clinical Specialty & $1978(z)$ & $1980(2)$ & $\begin{array}{c}1980 \\
\text { Increase } \\
\end{array}$ \\
\hline Maternity Nursing & $84(11,8)$ & $257 \quad(9.5)$ & 2064 \\
\hline Pediatric Nursing & $38 \quad(5.3)$ & $96 \quad(3.5)$ & $153:$ \\
\hline Medical-Surgical Nursing & $239(33.6)$ & $847(31.5)$ & ?s, \\
\hline Psychiatric Nursing & $31 \quad(4.4)$ & $85 \quad(3.2)$ & 1746 \\
\hline Schoot Nursing & $73(10.2)$ & $32 ?(12,0)$ & $341:$ \\
\hline \multicolumn{4}{|l|}{ Other Community } \\
\hline (All Clinical) & $712(100.0)$ & $2691(100.0)$ & $278 \%$ \\
\hline
\end{tabular}




\begin{tabular}{|c|c|c|c|c|c|}
\hline \multicolumn{6}{|c|}{$\begin{array}{l}\text { Table } 2 \\
\text { School Nursing Articles in Newspapers per } \\
\text { One Million Population by Region } \\
\text { of the United States: } 1978 \text { and } 1980\end{array}$} \\
\hline \multicolumn{2}{|c|}{ Rank } & \multirow[t]{2}{*}{ Region } & \multicolumn{2}{|c|}{$\begin{array}{l}\text { Number of Articles per } \\
1 \text { Million Population }\end{array}$} & \multirow{2}{*}{$\begin{array}{r}\begin{array}{l}\text { Percent } \\
\text { Increase }\end{array} \\
1980\end{array}$} \\
\hline 1980 & 1978 & & 1978 & 1980 & \\
\hline 1 & 3 & West North Centra? & .77 & 4.77 & $519 \%$ \\
\hline 2 & 4 & New England & .40 & 4.20 & $950 \%$ \\
\hline 3 & 1 & Mountain States & 1.08 & 2.46 & $128 \%$ \\
\hline 4 & 6 & West South Central & .18 & 1.64 & $811 \%$ \\
\hline 5 & 2 & Pacific & .79 & 1.57 & $99 \%$ \\
\hline 6 & 8 & East North Centra? & .12 & .67 & $458 \%$ \\
\hline 7 & 9 & East South Central & .07 & .55 & $686 \%$ \\
\hline 5 & 8 & Mid Atlantic & .21 & .52 & $148 \%$ \\
\hline 7 & 9 & South Atiantic & .14 & .25 & $79 \%$ \\
\hline
\end{tabular}

second in prevalence $(19 \%)$. This same pattern was seen for all other nursing articles. However, other clinical articles were significantly $\left[X_{m 1}^{2}(2)=24.38, \phi=.08\right.$, $p<.001]$ less likely to be news reports $(64 \%)$ and more likely to be feature stories (29\%). Although very little change in school nursing article type was seen during the two study years, feature articles declined from $22 \%$ to $18 \%$. The physical size of school nursing articles decreased from a mean of $58 \mathrm{sq}$. in. in 1978 to $42 \mathrm{sq}$. in. in $1980[\mathrm{t}(402)=3.26, \mathrm{p}<.01)$. School nursing articles were significantly smaller ( $X=53.01$ square inches) than articles about other clinical nursing specialities [t(3459) $=2.73, \quad p<.01]$. However, the clinical specialty articles, including school nursing articles, were significantly larger than articles $(X=39.88$ sq. in.) about all other nursing topics $[\mathrm{t}(17652)=2.31, \mathrm{p}<.05]$.

In addition to a diminished physical size, the emphasis on nursing as the primary focus of school nursing articles decreased in $1980\left[\mathrm{X}_{\mathrm{m} 1}^{2}(1)=12.62\right.$, $\phi=.16, p<.01]$. Many articles in 1980 focused primarily on teachers, school boards, general funding concerns and other issues, and only secondarily on school nursing. Thus it can be concluded that not only was the visibility of school nursing in newspapers low during the year studied, but there was also a decline in visibility from 1978 to 1980 . Also, very few school nursing articles in either year (10 in 1978 and 51 in 1980) made the front page.

\section{Demographic Characteristics of School Nurses in Newspapers}

The sex of the school nurses differed significantly between the two years $\left[X_{m i}^{2}(1)=5.35, \phi=.17, p<.05\right]$. Although female nurses predominated in both years, $5 \%$ of the nurses were male during 1978 vs .5\% during 1980. For other clinical nursing specialties, the incidence of reporting the existence of men in nursing was similar to that of school nursing articles $(9 \%)$ in 1978 , but very different in 1980. Men in school nursing were virtually absent in 1980 school nursing articles but comprised $8 \%$ of the nurses in other clinical nursing articles $\left[\mathrm{X}^{2}(1)=17.2, \phi=.09, \mathrm{p}<.0001\right]$. The educational level of nurses in newspapers was not usually specified. However, when it was identified, the BSN was considerably higher for school nursing $(18 \%)$ than for other clinical specialties $(6 \%)$ in 1978 . This difference did not hold up in 1980. 


\section{School Nurse Services}

The majority of articles on school nursing published during 1978 and 1980 described the types of services provided (Table 3 ). These articles usually began by explaining that illness and injury care actually constituted a small part of the school nurse's work, and then described other services such as screening and health education. The frequency with which this approach was encountered suggested that newspaper reporters assessed a public need for more information about school nursing services.

Preventive care was emphasized in articles about school nursing. School nursing articles were more likely to focus on prevention than were other clinical nursing specialties $\left[\mathrm{X}^{2}(2)=58.65, \phi=.26, \mathrm{p}<.0001\right]$. However, a significant decrease was seen in emphasis on prevention from 1978 to $1980\left[\mathrm{X}^{2}(2)=8.80, \phi=.16, \mathrm{p}<.05\right]$. On the other hand, descriptions of technical procedures (especially illness and injury care, and screening) increased in the 1980 sample $[t(402)=2.02, p<.05]$, as did portrayals of the school nurse as a contributing member of the health care team $[\mathrm{t}(402)=2.82, \mathrm{p}<.01]$, and as someone whose professional judgment and decision-making skills were important to the student's well-being $[\mathrm{t}(402)=5.43, \mathrm{p}<.001]$.

\section{Resources for School Nursing Services}

School nursing services cannot be provided without adequate funding to support salaries and supplies. Almost $30 \%$ of the articles reported problems with funding the school nursing programs (Table 4). Not only were existing funds reported to be inadequate, but also at least $20 \%$ of the articles reported reductions in funding for school nurse positions, and therefore, nurs-

\begin{tabular}{|lrr|}
\hline \multicolumn{4}{|c|}{$\begin{array}{c}\text { Table 3 } \\
\text { Description of School Nurse Services }\end{array}$} \\
\hline & $\begin{array}{r}\text { Percent of articles } \\
1978\end{array}$ & 1980 \\
Type of Service & $24 \%$ & $46 \%$ \\
Inlness and Injury Care & $35 \%$ & $47 \%$ \\
Screening (Vision, hearing, etc.) & $41 \%$ & $37 \%$ \\
Health Education & $13 \%$ & $16 \%$ \\
Mental Health/Counseling Services & $22 \%$ & $14 \%$ \\
Immunization Supervision & $6 \%$ & $9 \%$ \\
Adolescent Sexuality Issues & $6 \%$ & $5 \%$ \\
Reporting Child Abuse/Neglect & $2 \%$ & $5 \%$ \\
Substance Abuse Issues & & \\
& & \\
Proportion of Articles Describing Services & $80 \%$ & $76 \%$ \\
\hline
\end{tabular}

\begin{tabular}{|c|c|c|}
\hline \multicolumn{3}{|c|}{ 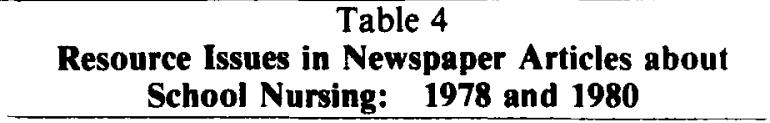 } \\
\hline \multirow[b]{2}{*}{ Issue } & \multicolumn{2}{|c|}{ Percent of articles } \\
\hline & 1978 & 1980 \\
\hline Loss of funding for school nurse positions & $20 \%$ & $21 \%$ \\
\hline Existing funds insuffictent to sustain services & $9 \%$ & $8 \%$ \\
\hline Excessive workioad & $9 \%$ & $6 \%$ \\
\hline New funds appropriated & $7 \%$ & $15 *$ \\
\hline Announcement of pay increases & $2 \%$ & 13 \\
\hline Proportion addressing resource 1ssues & $48 \%$ & $31 \%$ \\
\hline
\end{tabular}

ing services. Evidence of a growing movement to save school nursing services was found. In 1978 only one article made any mention of a school nurse speaking out against the cuts. During $1980,8 \%$ of the articles reported public protests by school nurses affected by the cuts. Protests by teachers and school administrators were found in $8 \%$ of the articles; parent groups were reported to protest cuts in school nursing services in $\mathbf{9 \%}$ of the articles.

There was no evidence of the success of school nurses', or teachers', or school administrators' efforts to prevent cuts in funding for school nursing services. However, the 1980 articles indicated that parent groups had been increasingly successful lobbyists for school nursing programs in some communities. The 1978 articles reported that parents were often uninformed about cuts until well into the next school year - after the nurses were gone and the funds reallocated. The 1980 articles pointed out that announced (but not yet implemented) cuts were quickly rescinded after the PTA or other parent groups presented petitions opposing the cuts.

\section{Praise and Criticism of School Nurses}

For the most part, school nurses received high praise in the newspapers during 1978 and 1980 . Parents (9\%), teachers and school administrators $(8 \%)$, and local physicians $(2 \%)$ usually voiced strong support for the efforts of school nurses to improve and protect children's health. The most frequent demand from these individuals and groups was for increased coverage and services. More than $80 \%$ of the newspaper articles praised school nursing as a vital force for improving the health of the nation's school children.

Criticism of school nurses in newspapers was rare. Only one such article was found in the 1978 sample: a teachers' union official complained that school nurses were not taking action against cuts in the school nursing program. The official argued that the teachers' union 
could help the nurses, but could not fight the battle alone. Negative comments were slightly more frequent in the 1980 sample. A PTA group in Buffalo, New York, criticized the part time availability of their school nurses and their lack of training in cardiopulmonary rescusitation. ${ }^{*}$ Thus, this article, while critical of aspects of the local school nursing program, showed the PTA to be a stronger supporter of quality in the school nursing program. The only instance of parental condemnation of school nursing per se occurred when masters-prepared school nurse practitioners in Toole County, Utah, asked the community if it wanted gynecological examinations, and pregnancy and contraceptive counseling made available in the high schools. The community rejected the offer of such services. A small group of parents was sufficiently distraught to attempt to have the school nurse practitioners removed. The group spokesperson contended that any care not mandated by law would undermine parent responsibility for their children's health. ${ }^{9-11}$ The 1980 sample also produced the only complaint by a student. A high school senior criticized her school nurse for informing the student's teachers about her suicide attempts, violating her privacy. The physician columnist acknowledged the student's feelings of distress, but also mentioned that teachers may need information from the school nurse in order to assist the student.

\section{DISCUSSION}

These data suggest that school nursing has not yet attained a position on the public's agenda of important social issues. This conclusion was based on the relatively small number of newspaper articles published on this topic, the low attention-getting nature of other than front page placement for most of the articles and modest visibility and circulation of the newspapers in which they appeared. Nevertheless, a perceptible increase in newspaper coverage has occurred.

A third of the school nursing articles addressed inadequate resources for school nursing services. School budget cutting is a political process in which the largest cuts will typically be made in the services that generate the leas! pressure either from the public or from other sources of community influence. Newspapers revealed the powerful influence that parents were able to exert on school budget decisions, especially when they formed organized pressure groups. These data showed that while teachers have been a valuable source of support for school nurses, parent groups are the most effective political constituency for school nursing services. Newspaper articles also indicated that the parent groups were most successful when they were able to argue against proposed cuts rather than waiting to react after the fact.
After the cuts were accomplished, parent groups faced a more difficult task. Essentially, they were in the position of asking for "new" services from a financially strapped system. Thus, it is essential that school nurses develop strong ties and excellent communication with parent and teacher organizations on an on-going basis rather than waiting until a crisis is at hand. Nurses must then use these ties to keep their constituency informed of any potential or real threats to the school nursing program.

The newspapers should serve an important role in communication between nurses and parents. Thus school nurses can build their base of public support by developing relationships with reporters, and using those ties to help reporters obtain the information needed to write articles supportive of school nursing. Encouraging the publication of feature articles about local school nurses will be especially helpful since this type of article is an excellent vehicle for informing parents about the value of the services. For example, articles that explained vision screening often mentioned that the cause of a child's failure to read was discovered by the school nurse during a routine screening. The "human interest" approach of feature articles permitted the reporter to make value judgments about the services. In every case, feature articles were supportive of school nursing.

There are approximately 30,000 full-time school nurses employed by the 16,000 public school districts in the United States. They offer a range of preventive and educational health services to the bulk of the total child and adolescent population, which in 1981 numbered 16 million in the age five-nine category, 18 million in the 10-14 range and 20 million in the $15-19$ age group. Rather than simply reacting to budget cuts in the school nursing programs, school nurses should launch a massive effort to enlarge the scope of their activities by gaining taxpayer support for some very cost effective services.

This challenge was offered by the Select Panel for the Promotion of Child Health appointed by the Secretary of Health and Human Services and the Congress. In its 1981 report, Better Health for Our Children: A National Strategy, the panel favored school-based health services as an efficient way of providing primary health services to school children and certain preschool children. They recommended that both state and federal governments expand school-based primary care by:

- The adoption of State laws and policies to permit full use of nurse practitioners .... in offering a wide range of educational, preventive, and primary care services to children

- The further support of demonstrations in Medicaid reimbursement and the pooling of various public 
sources of support for child health services rendered in selected school settings

- Particular attention given to school-based services for adolescents

- Schools and school systems without such comprehensive primary care programs should utilize professionally qualified nurses to provide health education, counseling, and preventive services, to work with parents to link children with other health services, and provide professional nursing supervision for children with chronic illness or handicapping conditions

- These nurses should undertake a vigorous linking and followup role pegged to school entry health requirements and should help to implement Public Law 94-142, serve as liaison to the home, and provide professional nursing supervision for children with chronic illness or handicapping conditions, many more of whom are now in regular schools as a result of PL 94-142.

- School nurses should be trained in physical assessment, have indepth education in child development, family counseling, anticipatory guidance, and learning problems; to be able to deal with common physical problems and refer others; have a basic public health background; be skilled in basic methods of individual and group health education, and have an indepth orientation to referral sources in the community ${ }^{3}$

Unfortunately, our clipping service data base reveals that none of these recommendations have received public discussion in the newspapers of any town or city. Because the priorities of school authorities have not necessarily agreed with those of the health authorities, school nursing often has been treated as a marginal and possibly expendable service. The lack of parent advocacy in maintaining and expanding school nursing is directly related to its absence as an issue on the local public agency which is predominately created by the news media of every community.

\section{References}

1. Oda D: School nursing: current observations and future projections. J Sch Health 49(8):437-439, 1979

2. Resnick $M$, Blum $\mathbf{R}$, Hector $\mathbf{J}$ : Adolescent nerceptions of the school nurses, J Sch Health 50(10):551-554, 1980.

3. U.S. Department of Health and Human Services, Select Pand for the Promotion of Child Health: Better Heallh for Our Childre'n: a National Strategy. Vols. 1-5 Washington DC, Ciovernment Printing Office, 1981.

4. Berelson B: Content Analysis in Communication Research. New York, Hafner, 1952.

5. Budd R, Thorp K: Coment Analesis of Commmicanions. Neu York. MacMillan, 1967.

6. Gerbner G: The Analysis of Communication Content. New York, Wiley, 1979.

7. Holsti O: Comtent Analysis for the Social Sciences and Humanities. Boston, Addison-Wesley, 1969.

8. School board supports health nurse program. The Transcripl (newspaper). Toole, Utah, May 15, 1980.

9. Cole D: Groups try to block school nurse work. The Salt late Tribume. May 17, 1980.

10. Associated Press. School nurse program both hit. defended. The Siandard-Examiner (newspaper). May 18, 1980

11. Hollins D: School nurse situation deplored. Buffolo Evaning New. March 12, 1980.

Beatrice J. Kalisch, RN, EdD, is Titus Professor of Nursing, Chair, Parent-Child Nursing and Coinvestigator, Information Quality of Nursing News Research Project. Philip A. Kalisch, PhD, is Professor. History, Politics and Economics of Nursing and Coinvestigator, Information Quality of Nursing News Research Project. Mary McHugh, RN, MSN, is Research Associate, Information Quality of Nursing News Research Project. All work at the University of Michigan, Ann Arbor. MI 48104.

\section{ANA Convention}

"Challenges and Choices" is the theme for the American Nurses' Association 1984 Convention to be held June 22-28 in New Orleans. Featured speakers will be Jeffrey Halletl, president of The Naisbitt Group, and Judy Woodruff, Washington correspondent for the Public Broadcasting System's "MacNeil-Lehrer News Hour."

Hallett will discuss the 10 major trends identified in John Naisbitt's best-seller Megatrends and the effect of those trends on future health care. Woodruff will moderate a panel discussion on nursing issues and nursing's professional choices in the evolving high tech/high touch environment.

For more information on the convention, write: Marketing, American Nurses' Association, 2420 Pershing Rd., Kansas City, MO 64108. 